\title{
Ischemic Preconditioning Inhibits Mitochondrial Permeability Transition Pore Opening through the PTEN/PDE4 Signaling Pathway
}

\author{
Xiaoxu Zheng ${ }^{a} \quad$ Lingyun Zu $^{a}$ Lewis Becker ${ }^{a}$ Zheqing P. Cai ${ }^{a}$ b \\ a Division of Cardiology, Department of Medicine, Johns Hopkins University School of Medicine, Baltimore, Md., and \\ ${ }^{\mathrm{b}} \mathrm{CL}$ Laboratory, Abingdon, Md., USA
}

\section{Key Words}

Akt $\cdot$ Ischemic preconditioning $\cdot$ Mitochondrial permeability transition pore · PDE4 - PTEN

\begin{abstract}
Objectives: Ischemic preconditioning (IPC) induces cardioprotection against ischemia-reperfusion (IR) injury by inhibiting the mitochondrial permeability transition pore (mPTP). Here, we tested the hypothesis that IPC-induced cardioprotection is mediated by the phosphatase PTEN and PDE4 (phosphodiesterase 4). Methods: Isolated hearts from wildtype mice (WT, $\mathrm{n}=110)$ and myocyte-specific PTEN-knockout mice (PKO, $n=94$ ) were exposed to IPC or control conditions followed by IR. Subcellular fractionation was performed by sucrose gradient ultracentrifugation. Results: IPC limited myocardial infarct size (IS) in WT mice. The PDE4 inhibitor rolipram abolished the protective effect of IPC. However, small IS was found in PKO hearts after IR, and IPC did not decrease IS but enlarged it in PKO hearts. IPC promoted PDE4D localization to caveolin-3-enriched fractions in WT mice by increasing Akt levels at the caveolae. In PKO hearts, basal PDE4D levels were elevated at the caveolae, and IPC decreased PDE4D levels. Consistent with the subcellular PDE4D protein levels and its activity, elevation in intracellular $\mathrm{Ca}^{2+}$ levels in the ischemic heart and opening of MPTP after IR
\end{abstract}

were inhibited by IPC in WT mice, but not by IPC in PKO mice. Conclusions: IPC inhibits mPTP opening by regulating the PTEN/PDE4 signaling pathway.

(c) 2014 S. Karger AG, Basel

\section{Introduction}

Reperfusion following prolonged ischemia causes substantial myocardial injury, contributing to mortality and morbidity of myocardial infarction $[1,2]$. Ischemic preconditioning (IPC), consisting of one or several brief periods of ischemia and reperfusion, generates powerful protection against ischemia-reperfusion (IR) injury [3]. However, the molecular mechanism underlying IPC is still poorly understood [4]. Reperfusion saves the ischemic myocardium, but it results in calcium overload, which is an important factor in promoting mitochondrial permeability transition pore ( $\mathrm{MPTP}$ ) opening and subsequent cell death $[2,5,6]$. It has been reported that IPC inhibits $\mathrm{mPTP}$ opening through activation of Akt [7].

Akt activity is regulated by phosphatidylinositol (PI) 3-kinase (PI3K) and PTEN (phosphatase and tensin homologue deleted on chromosome ten). PI3K activates Akt by phosphorylating PI bisphosphate to PI 3,4,5-triphosphate (PIP3) at the plasma membrane, whereas

\section{KARGER}

E-Mail karger@karger.com

www.karger.com/crd
(C) 2014 S. Karger AG, Basel

0008-6312/14/1293-0163\$39.50/0
Dr. Zheqing P. Cai

501 Callander Way

Abingdon, MD 21009 (USA)

E-Mail czheqing@ cardio-lab.com 
PTEN reverses this process, leading to Akt inactivation [8]. Akt can be localized to caveolae (lipid-rich microdomains of the plasma membrane) [9]. Caveolae are essential for IPC induction [10-12]. However, many studies have suggested that Akt mediates cardioprotection against IR injury by regulating translocation of Bcl-2 family proteins and glycogen synthase kinase (GSK)- $3 \beta$ from the cytosol to the mitochondria $[9,13-16]$. Where Akt exerts its protection against IR injury has not been defined.

Caveolae contain many signaling molecules involved in the regulation of calcium influx, including L-type calcium channels, $\beta$-adrenoceptors and cAMP-dependent protein kinase (PKA) [17]. The formation of caveolae is promoted by its structural protein caveolin (Cav) [18]. There are three Cav isoforms, and Cav-3 is myocyte specific [19]. Cav-3 acts as a scaffolding domain to assemble signaling complexes [20]. L-type calcium channels are activated by PKA, but local cAMP levels are mainly dependent on PDE4 (phosphodiesterase 4) activity [21]. Decreased PDE4 activity has been implicated in the pathogenesis of heart failure and arrhythmias [22]. PDE4D is the major isoform of PDE4 existing in rodent hearts. PDE4D can be recruited to the plasma membrane through $\beta$-arrestin [23]. In the present study, we tested the hypothesis that IPC promotes PDE4D localization to the plasma membrane through PTEN inactivation, preventing calcium entry and $\mathrm{mPTP}$ opening after IR.

\section{Methods}

\section{Animals}

All experiments were performed with age-matched male mice. At the time of the experiments, mice were 8-10 weeks old. Myocyte-specific PTEN knockout (PKO) mice (Pten ${ }^{\text {loxp/loxp }} ; \mathrm{ckm}$ $\mathrm{Cre}^{+/-}$) were generated by loxp-cre technology. Their phenotypes were described previously [24]. Briefly, PKO mice are characterized by physiological cardiac hypertrophy. All procedures were approved by our Institutional Animal Care and Use Committee and conformed to the Guide for the Care and Use of Laboratory Animals published by the US National Institutes of Health (NIH Publication No. 85-23, revised 1996).

\section{Mouse Langendorff Preparation}

The Langendorff preparation was performed as described previously [25]. Briefly, after mice were anesthetized with pentobarbital $(70 \mathrm{mg} / \mathrm{kg})$, hearts were isolated. The ascending aorta was cannulated with a blunt needle. The heart was perfused at a constant pressure of $100 \mathrm{~cm} \mathrm{H}_{2} \mathrm{O}$ with modified Krebs-Henseleit buffer (in mM: glucose 17, $\mathrm{NaCl} 120, \mathrm{NaHCO}_{3} 25, \mathrm{CaCl}_{2} 2.5, \mathrm{KCl} 5.9, \mathrm{MgSO}_{4}$ 1.2 and EDTA 0.5), which was maintained at $37^{\circ} \mathrm{C}$ and bubbled continuously with a mixture of $95 \% \mathrm{O}_{2}$ and $5 \% \mathrm{CO}_{2}$. Global ischemia was induced by cessation of perfusion, followed by reperfu- sion. Isolated hearts from wild-type (WT) mice and $\mathrm{PKO}$ mice were exposed to IPC, consisting of 10-min ischemia and 5-min reperfusion (I-10/R-5) or an equivalent period of normal perfusion followed by $30-\mathrm{min}$ ischemia and 120-min reperfusion (I-30/R-120).

\section{Assessment of Myocardial Infarct Size}

Infarct size (IS) was determined as described previously [25]. At the end of experiments, mouse hearts were perfused with triphenyltetrazolium chloride for $1 \mathrm{~min}$ and then incubated with $1 \%$ triphenyltetrazolium chloride at $37^{\circ} \mathrm{C}$ for $15 \mathrm{~min}$. After freezing at $-80^{\circ} \mathrm{C}$, hearts were transected into 5 pieces, each of which was weighed. Cardiac sections were incubated with $10 \%$ formalin for 30 min. Both sides (A and B) of each section were photographed. Viable myocardium stains red and infarcted tissue was white. The areas of red and white color in the left ventricle (LV) and the muscle area of cardiac sections were measured by computerized planimetry (ImageJ; NIH, Bethesda, Md., USA). Total LV infarct weight was determined by the equation: $\left[\left(S_{1} / C_{1} \times W_{1}\right)+\left(S_{2} / C_{2} \times\right.\right.$ $\left.\left.W_{1}\right)+\left(S_{2} / C_{2} \times W_{2}\right)+\left(S_{3} / C_{3} \times W_{3}\right)+\left(S_{4} / C_{4} \times W_{4}\right)+\left(S_{5} / C_{5} \times W_{5}\right)\right]$, where $S$ is the area of $L V$ infarction for the slice represented by the subscript, $\mathrm{C}$ is the muscle area of the cardiac section, and $W$ is the weight of that respective section. Total weight of viable myocardium in LV was calculated in a similar fashion. IS was calculated as a percentage of LV as follows: IS/LV = total infarct weight/(total infarct weight + total weight of viable myocardium $) \times 100 \%$.

\section{Subcellular Fractionation}

Enrichment of caveola membranes with detergent-free reagents was performed as described previously [26]. Briefly, hearts were homogenized in $0.5 \mathrm{M}$ sodium carbonate $(\mathrm{pH} 11)$. The homogenate was suspended in an equal volume of $80 \%$ sucrose prepared in MES-buffered saline. The solution was placed at the bottom of an ultracentrifuge tube, overlaid with 5-35\% discontinuous sucrose gradient followed by $16 \mathrm{~h}$ of centrifugation at $38,000 \mathrm{rpm}$. After centrifugation, 12 gradient fractions $(1 \mathrm{ml})$ were concentrated by precipitation with trichloroacetic acid. The pellets of the 12 fractions (from top to bottom) were washed and dissolved in sample buffer and loaded onto 12 lanes (from left to right, respectively) of one SDS-PAGE gel.

\section{Measurement of PDE4 Activity}

PDE4 activity was measured by a PDE-Glo ${ }^{\mathrm{TM}} \mathrm{PDE}$ assay kit (Promega Corp., Madison, Wisc., USA). PDE4 negatively regulates cAMP levels. cAMP binds the inactive PKA holoenzyme. Released catalytic subunits of PKA consume ATP. The level of remaining ATP was measured by luminescence assay using the luciferase-based Kinase-Glo reagent. PDE4 activity is directly proportional to the remaining ATP levels. According to the manufacturer's instructions, $10 \mu \mathrm{g}$ of Cav-3-enriched membrane protein were incubated with cAMP $(1 \mu \mathrm{M})$ to initiate the PDE reaction. The PDE-Glo ${ }^{\mathrm{TM}}$ termination buffer containing the PDE4 inhibitor (rolipram, Ro, $100 \mu \mathrm{M}$ ) and detection solution were added and mixed well. The Kinase-Glo reagent was added and incubated for $10 \mathrm{~min}$ at room temperature. Luminescence was measured using a platereading luminometer.

Assessment of Intracellular $\mathrm{Ca}^{2+}$ Levels

Intracellular free $\mathrm{Ca}^{2+}\left[\mathrm{Ca}^{2+}\right]$ levels were measured with a Rhod-2 AM fluorescent probe (Anaspec Inc., Fremont, Calif., USA) as previously described, with modifications [27]. Rhod-2 
$\mathrm{AM}$ is membrane permeable and becomes $\mathrm{Ca}^{2+}$-sensitive fluorescence probe when trapped in the cytosol and deesterified to Rhod2 . Rhod- 2 dye $(25 \mu \mathrm{g} / \mathrm{ml}$ in $2 \mathrm{ml})$ was added without recirculation through a parallel infusion line just above the aortic cannula. During loading, only the bolus line was opened. Dye loading was followed by a 10 -min washout period with the perfusion buffer to remove extracellular dye. Ro was added into the perfusion line during the washout. At the end of the experiment, heart tissues were homogenized in $\mathrm{Ca}_{\mathrm{i}}{ }^{2+}$-free Krebs-Henseleit buffer. Equal amounts $(100 \mu \mathrm{g})$ of protein from each sample were loaded into each well. Plates were read at $531 \mathrm{~nm}$ (excitation) and $593 \mathrm{~nm}$ (emission).

\section{Measurement of MPTP Opening in Isolated Hearts}

$\mathrm{mPTP}$ opening in mouse hearts was assessed as previously described, with modifications [28]. Briefly, isolated hearts were balanced with the perfusion buffer and loaded with $1 \mu \mathrm{M}$ calcein-AM (Anaspec Inc.) for $15 \mathrm{~min}$. During the last $5 \mathrm{~min}$ of calcein-AM perfusion, $\mathrm{CoCl}_{2}(200 \mu \mathrm{M})$ was added into the perfusion line to quench the cytosolic calcein signal. Remaining calcein in the extracellular space was washed out with a 10 -min perfusion in the absence or presence of inhibitors, followed by I-30/R-15. At the end of the experiment, heart tissues were homogenized on ice in calcium-free buffer, followed by centrifugation at $12,000 \mathrm{rpm}$ for $10 \mathrm{~min}$. Supernatants (cytosolic fractions) were collected for protein concentration measurements. Calcein fluorescence was measured at $484-\mathrm{nm}$ excitation and $520-\mathrm{nm}$ emission in $100 \mu \mathrm{g}$ of protein. Without IR, low fluorescence intensity was detected in the cytosolic fractions while high fluorescence intensity was found in the mitochondrial fractions (from pellets after centrifugation), suggesting that $\mathrm{mPTP}$ were closed. Inhibitors were added into the perfusion line $5 \mathrm{~min}$ before I-30.

\section{Immunoprecipitation and Immunoblotting Assay}

Cardiac tissues were homogenized in lysis buffer (in mM: Tris 20, $\mathrm{NaCl} 150$, EDTA 1, EGTA 1, PMSF 1, $\mathrm{Na}_{3} \mathrm{VO}_{4} 1 ; 1 \%$ Triton; $\mathrm{pH}$ 7.5). Heart lysates were incubated with primary antibody overnight at $4{ }^{\circ} \mathrm{C}$. The target protein was pulled down following 2 -hour incubation with G-protein agarose beads. Proteins were detected using primary antibodies, followed by horseradish peroxidaseconjugated secondary antibody and enhanced chemiluminescence. Antibodies against PTEN, $\beta$-arrestin, p-Akt (S-473) and total Akt were purchased from Cell Signaling Technology (Danvers, Mass., USA). PDE4D antibody was from Santa Cruz Biotechnology (Santa Cruz, Calif., USA).

\section{Statistical Analysis}

Data are presented as means \pm SEM. Differences among groups were analyzed using ANOVA with the Tukey post hoc test and considered significant if $\mathrm{p}<0.05$.

\section{Results}

\section{PTEN and PDE4 Are Required for IPC-Induced}

Cardioprotection against IR Injury

We previously reported that PTEN inactivation confers cardioprotection against IR injury in isolated mouse hearts [25]. In the present study, IPC decreased IS in WT (IPC/WT) mice. Small IS was seen in control $(\mathrm{CON}) / \mathrm{PKO}$ mice. Surprisingly, IPC increased IS in $\mathrm{PKO}$ mice to levels similar to those seen in WT/CON mice (fig. 1), suggesting that IPC abolishes the native protection in $\mathrm{PKO}$ mice. Since PDE4 plays an important role in regulating local cAMP levels and L-type calcium channel activity, we wondered whether PDE4 is involved in cardioprotection induced by IPC and PTEN inactivation. Hearts from IPC/WT and CON/PKO were treated with Ro, a PDE4 inhibitor, followed by I30/R-120. Ro inhibited the infarct-limiting effect in these two groups (fig. 1). These results suggest that PTEN and PDE4 are necessary for IPC cardioprotection against IR injury.

\section{IPC Promotes Localization of Akt and PDE4D to the}

\section{Plasma Membrane by Regulating PTEN/Akt}

Many studies have reported that the PI3K/Akt signaling pathway plays an important role in IPC cardioprotection $[6,8]$. This signaling pathway cross talks with PTEN at the plasma membrane $[8,9]$. To determine whether PTEN inactivation affects Akt localization to the plasma membrane, subcellular fractionations were performed after exposure of isolated hearts to CON or IPC. The same volumes of samples from 12 fractions were loaded onto SDS-PAGE gels for protein analysis. Cav-3-enriched fractions were identified in lane 4 (fig. 2a). Only small amounts of Akt were localized at the subcellular domain (fig. 2b). To compare Akt protein levels, the same amounts of proteins from the Cav-3-enriched fractions were loaded onto SDS-PAGE gels. IPC increased Akt protein levels in WT mice (fig. 2c). The PI3K inhibitor LY20094 (LY) blocked this effect (fig. 2c). However, in PKO mice, there were high basal levels of Akt protein at the Cav-3-enriched fractions, and IPC decreased Akt protein levels when compared with $\mathrm{CON}$ (fig. 2c), suggesting that PTEN is required for Akt localization to the caveolae at the plasma membrane in IPC.

To determine whether Akt regulates PDE4D localization, PDE4D protein levels in 12 subcellular fractions and Cav-3-enriched fractions were measured. Under basal conditions, few amounts of PDE4D were detected in Cav3-enriched fractions, and PDE4D protein levels at the microdomain were regulated by the treatments (fig. 3a). IPC increased PDE4D protein levels compared with CON in WT mice, and this effect was inhibited by LY (fig. 3b). This suggests that $\mathrm{PDE} 4 \mathrm{D}$ localization to the caveolae requires Akt activation. Consistent with Akt protein levels, PDE4D protein levels were elevated under basal conditions in 
Fig. 1. Myocardial IS after IR. a Cardiac sections of 1 representative heart from each group. Isolated hearts from WT and PKO mice were exposed to CON (I-30/R-120) or IPC (I-10/R-5) plus I-30/R-120 in the absence or presence of Ro $(10 \mu \mathrm{M})$. After IR, the heart was cut into 5 sections and stained with triphenyltetrazolium chloride. Each group contains 6-8 hearts. b Analysis of IS. Myocardial infarct area was assessed by Image J software. $\mathrm{n}=6-8$ /group. ${ }^{\mathrm{a}} \mathrm{p}<0.01$ vs. CON/WT; ${ }^{\mathrm{b}} \mathrm{p}<0.01$ vs. IPC/WT; ${ }^{\mathrm{c}} \mathrm{p}<$ 0.01 vs. $\mathrm{CON} / \mathrm{PKO}$.

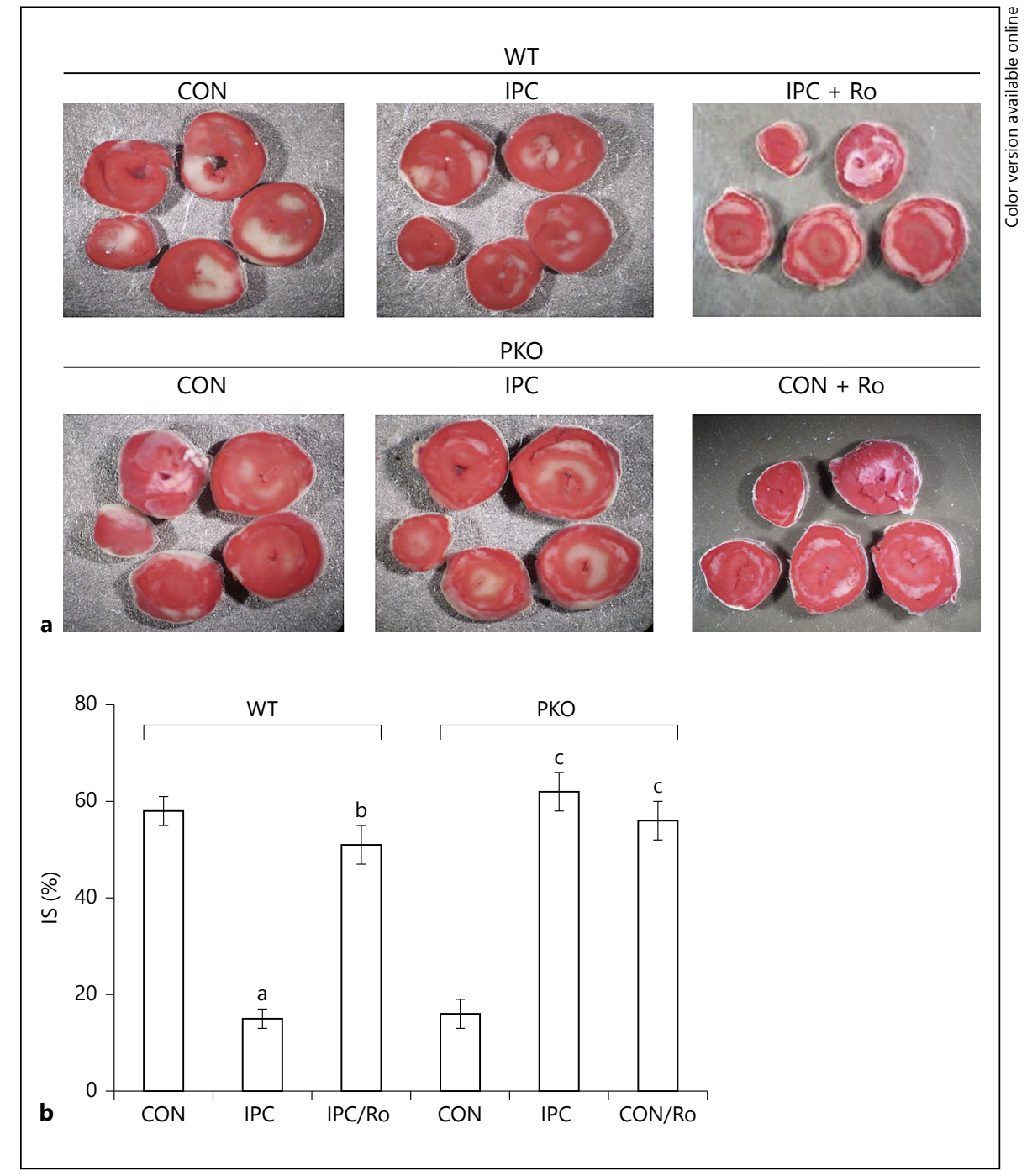

PKO mice (fig. 3b). IPC decreased PDE4D protein levels when compared with CON/PKO (fig. 3b). In a similar way, IPC increased PDE4 activity in Cav-3-enriched fractions in WT mice, and LY inhibited this effect. In PKO mice, PDE4 activity at the microdomain was increased under basal conditions; IPC decreased its activity (fig. 3c). Taken together, these results suggest that activated Akt modulates PDE4D protein levels at the caveolea.

IPC Promotes the Association between Akt,

$\beta$-Arrestin, and PDE4D at the Plasma Membrane

To determine whether the adaptor $\beta$-arrestin interacts with PDE4D and Akt, associations between $\beta$-arrestin, PDE4D and Akt were determined. Akt or PDE4D was pulled down from Cav-3-enriched fractions generated from WT/IPC hearts. The membrane was immunoblotted with $\beta$-arrestin antibody. $\beta$-Arrestin was found in the immunoprecipitates (fig. 4). In a reverse experiment, $\beta$-arrestin was pulled down from the same lysates and followed by immunoblotting of Akt or PDE4D. Akt and PDE4D were present in the immunoprecipitates (fig. 4). These results suggest that Akt is associated with $\beta$-arrestin and PDE4D at the plasma membrane.

\section{IPC Inhibits $\mathrm{Ca}^{2+}$ Overload in the Ischemic Heart through PDE4}

To determine whether PDE4D localization to the plasma membrane inhibits intracellular $\mathrm{Ca}^{2+}$ overload in the ischemic heart, we exposed isolated hearts from WT mice to nonischemia (NIS), I-30 (CON), I-10/R-5 plus I-30 in the absence or presence of Ro (IPC or IPC/Ro; fig. 5a). 
Fig. 2. IPC increases Akt localization to the plasma membrane through PTEN signaling. a, b Distribution of Cav-3 and Akt in subcellular fractions. Isolated hearts from WT or PKO mice were treated with no ischemia (CON), I-10/R-5 (IPC), IPC + LY $(10 \mu \mathrm{M})$ or CON + AI (Akt inhibitor, 20 $\mu \mathrm{M})$. Subcellular fractionations were performed with sucrose gradient centrifugation. Equal volumes of cell lysates were loaded onto SDS-PAGE gels. Protein expression of Cav-3 was determined. Representative blots from at least 3 independent experiments. c Akt protein levels in Cav3-enriched fractions. Equal amounts of protein from Cav-3-enriched fractions were loaded. $\mathrm{n}=4$ /group. ${ }^{\mathrm{a}} \mathrm{p}<0.01$ vs. CON/WT or IPC/LY; ${ }^{b} \mathrm{p}<0.01$ vs. CON/ PKO.

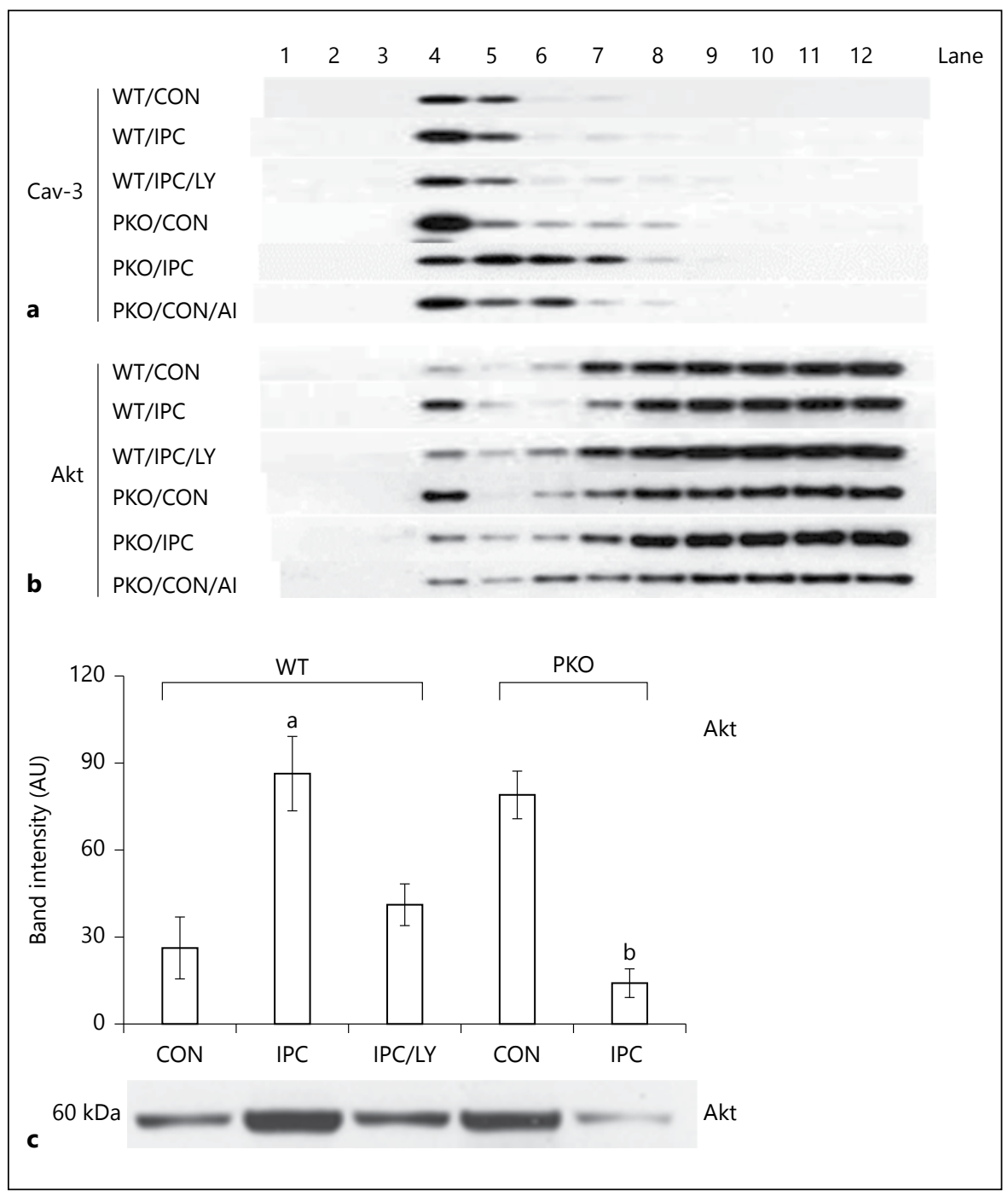

IPC decreased intracellular $\mathrm{Ca}^{2+}$ levels at the end of ischemia compared with CON/WT, and Ro abolished the inhibitory effect of IPC in the ischemic heart (fig. 5b). However, in PKO mice, there was no significant difference between NIS and CON (fig. 5b). Without PTEN, IPC increased intracellular $\mathrm{Ca}^{2+}$ levels in the ischemic heart compared with CON; moreover, Ro had a similar effect (fig. 5b).

\section{IPC Inhibits MPTP Opening in the Heart through PDE4}

Increased intracellular $\mathrm{Ca}^{2+}$ levels are directly associated with $\mathrm{mPTP}$ opening, leading to cell death. To determine whether IPC inhibits MPTP opening after IR, we exposed isolated hearts from WT mice to NIS, I-30/R-15 (CON), CON plus cyclosporine A (CsA), CON plus vera- pamil (Ve), I-10/R-5 plus CON (IPC) and IPC/Ro (fig. 6a). $\mathrm{CON}$ caused a significant increase in fluorescence intensity compared with NIS, indicating $\mathrm{mPTP}$ opening (fig. 6b). CsA or Ve inhibited the increase (fig. 6b), suggesting that the assay of MPTP opening was accurate. Consistent with the intracellular $\mathrm{Ca}^{2+}$ levels in the ischemic heart, IPC inhibited MPTP opening in WT mice, and this effect was abolished by Ro (fig. 6b). Moreover, hearts from PKO mice were exposed to NIS, CON, IPC, IPC/Ve and CON/Ro. CON did not cause mPTP opening in $\mathrm{PKO}$ mice; however, the protection was lost after IPC (fig. 6c). Ve reversed the detrimental effect of IPC, and Ro resulted in $\mathrm{mPTP}$ opening in $\mathrm{CON}$ (fig. 6c). These results suggest that $\mathrm{MPTP}$ opening is dependent on PDE4 and L-type calcium channel activities in the heart exposed to IR. 


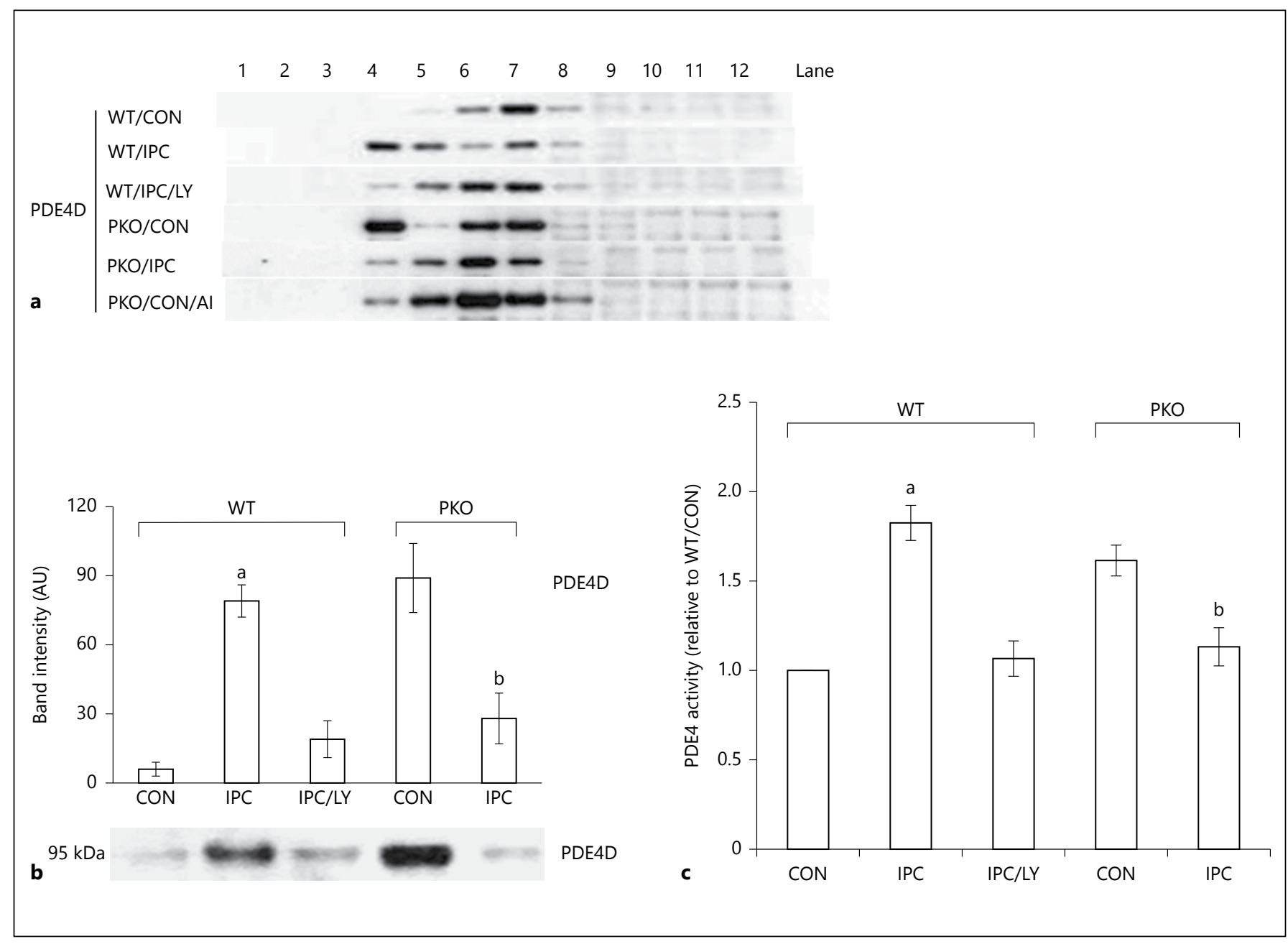

Fig. 3. Akt activation increases PDE4D localization to the plasma membrane. a Distribution of PDE4D in subcellular fractions. Isolated hearts from WT and PKO mice were exposed to CON, IPC, $\mathrm{IPC}+\mathrm{LY}$ or CON + AI, and followed by subcellular fractionation. Representative blots from at least 3 independent experiments. b PDE4D protein levels in Cav-3-enriched fractions. $n=4$ /group. ${ }^{\mathrm{a}} \mathrm{p}<0.01$ vs. CON/WT or IPC/LY; ${ }^{\mathrm{b}} \mathrm{p}<0.01$ vs. CON/PKO. c $\mathrm{PDE} 4$ activity in Cav-3-enriched fractions. $\mathrm{n}=6$ /group. ${ }^{\mathrm{a}} \mathrm{p}<0.05$ vs. CON/WT or IPC/LY; ${ }^{\mathrm{b}} \mathrm{p}<0.05$ vs. CON/PKO.
Fig. 4. IPC promotes associations between Akt, $\beta$-arrestin (Arr) and PDE4D in Cav3-enriched fractions. Cav-3 enriched fractions (M) from IPC/WT hearts were immunoprecipitated with an antibody against Akt or PDE4D, followed by immunoblotting with antibodies against $\beta$-Arr (a). In a reverse experiment, cell lysates were pulled down with $\beta$-Arr antibody, followed by immunoblotting with antibodies against Akt or PDE4D (b). Representative blots from at least 3 independent experiments. $\mathrm{W}=$ Whole cell lysates.

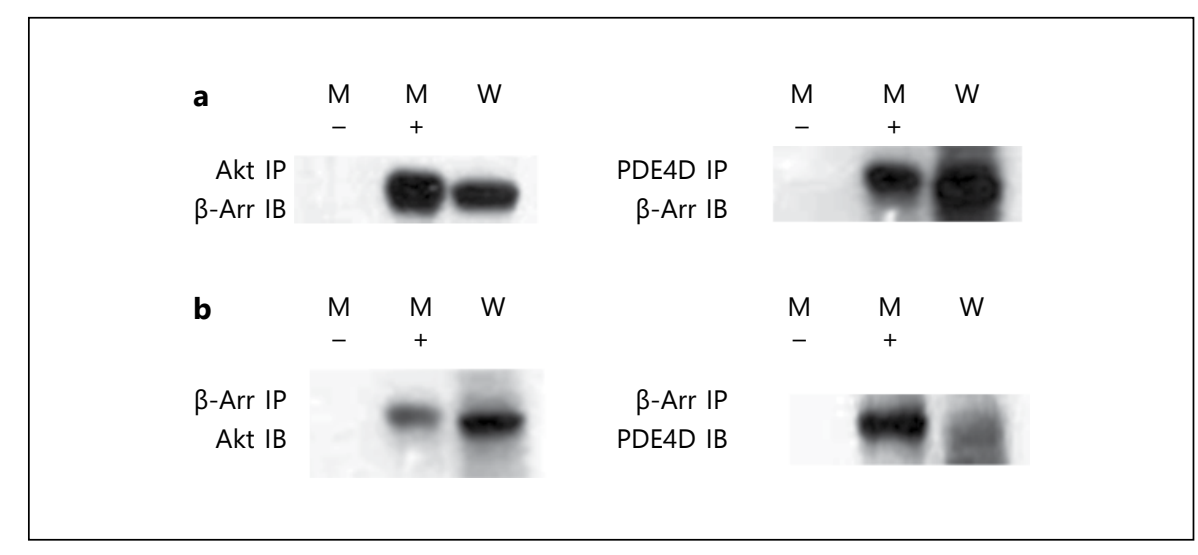


Fig. 5. Intracellular $\mathrm{Ca}^{2+}$ levels in ischemic hearts. a Experimental protocols. Isolated hearts from WT and PKO mice were loaded with the fluorescent dye Rod-2 (Rd), followed by a 10-min washout (Wo) and I-30. Ro was added into the perfusion line during washout. Preconditioning with I-10 and R-5 followed 5-min Wo. b Intracellular $\mathrm{Ca}^{2+}$ levels in WT and PKO hearts. $\mathrm{n}=$ 4/group. ${ }^{\mathrm{a}} \mathrm{p}<0.05$ vs. NIS/WT or IPC/WT; ${ }^{\mathrm{b}} \mathrm{p}<0.05$ vs. IPC/WT; ${ }^{\mathrm{c}} \mathrm{p}>0.05$ vs. NIS/ $\mathrm{PKO} ;{ }^{\mathrm{d}} \mathrm{p}<0.05$ vs. CON/PKO; ${ }^{\mathrm{e}} \mathrm{p}<0.01$ vs. CON/PKO.

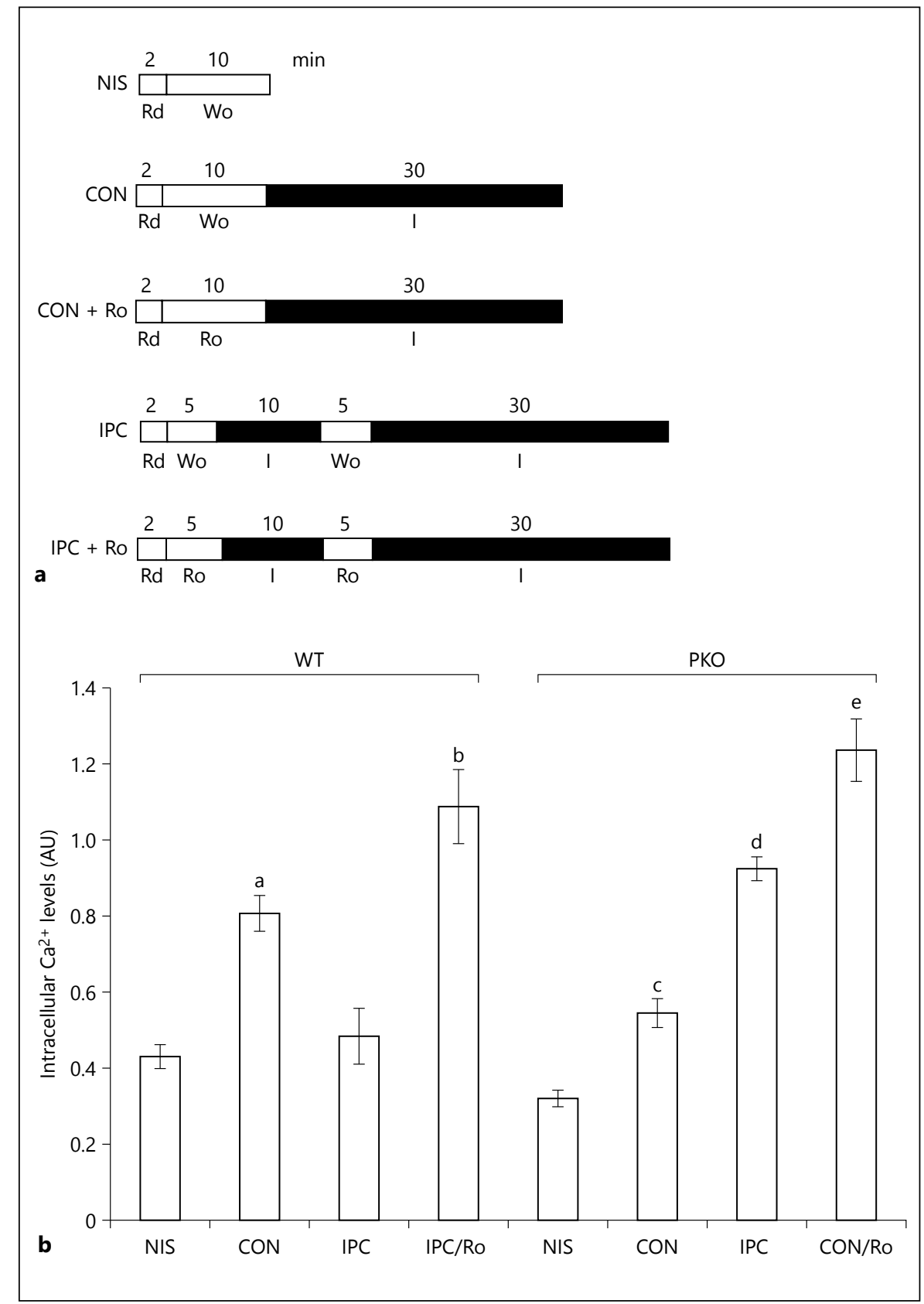

\section{Discussion}

In the present study, we report three important findings. First, we demonstrate that PTEN is required for IPC induction. In PKO mice, IPC did not reduce myocardial IS after IR. Second, we show that IPC promotes localization of PDE4D to the caveolae in the heart by regulating the PTEN/Akt pathway. Akt inhibition blocked PDE4D localization to the plasma membrane induced by IPC and
PTEN inactivation. Third, we demonstrate that PDE4 plays an important role in controlling calcium overload and $\mathrm{mPTP}$ opening. PDE4 inhibition abolished the inhibition of calcium overload and MPTP opening in IPC/ WT mice. Therefore, the present study has demonstrated that PTEN plays a critical role in response to ischemia and activation of the Akt/PDE4 signaling pathway at the plasma membrane. This may lead to inhibition of calcium overload and mPTP opening after IR. 


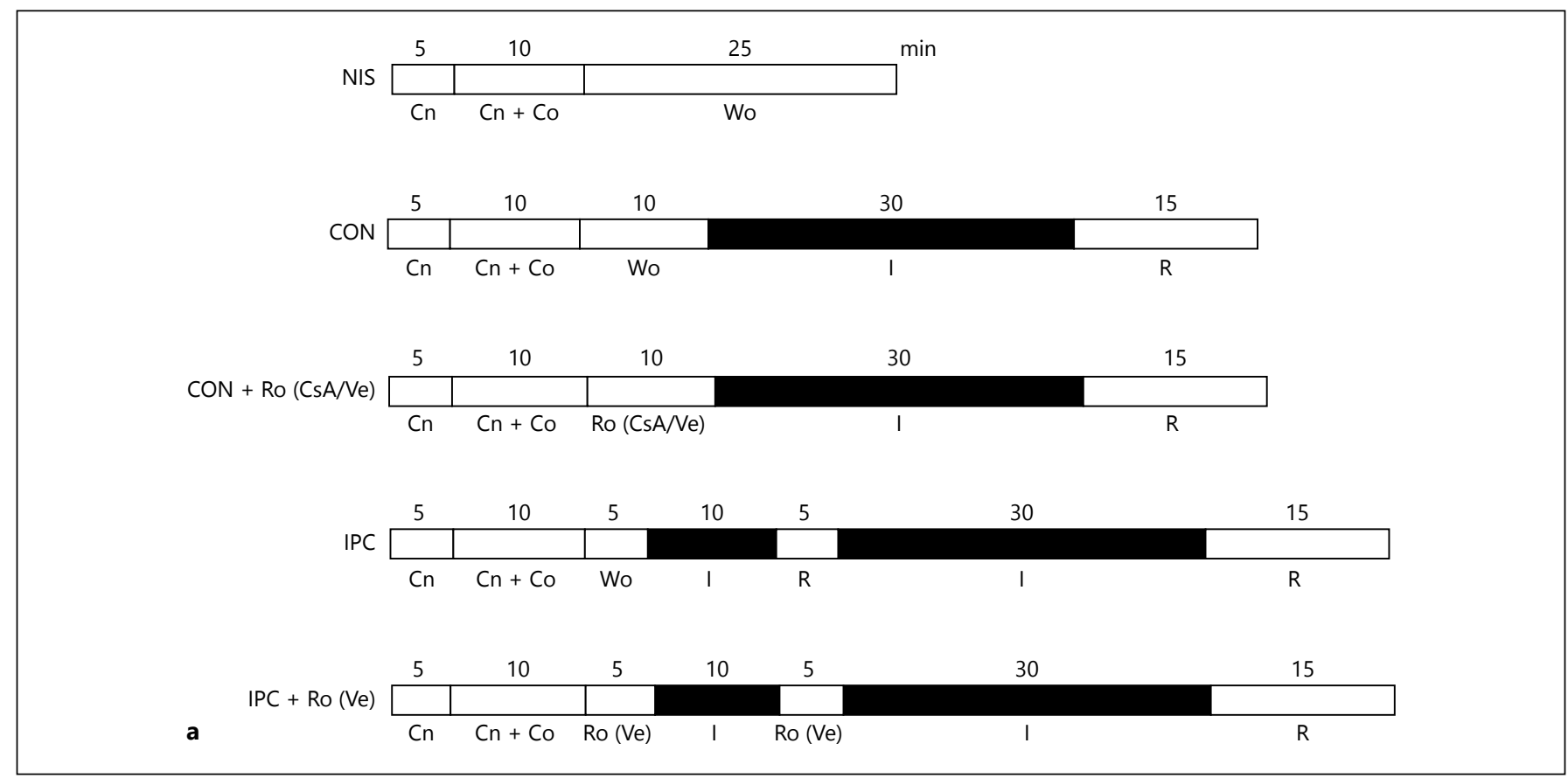

Fig. 6. mPTP opening after IR. a Experimental protocols. Isolated hearts from WT and PKO mice were loaded with the fluorescent dye calcein $(\mathrm{Cn})$ for $15 \mathrm{~min}$, followed by total 25 -min washout (Wo). Ro, CsA $(1 \mu \mathrm{M})$ or $\mathrm{Ve}(10 \mu \mathrm{M})$ was added during washout. $\mathrm{Co}=\mathrm{CoCl}_{2}$. b mPTP opening in WT after IR. $\mathrm{n}=5-8$ /group. ${ }^{\mathrm{a}} \mathrm{p}<0.01$ vs. NIS or IPC or CON/Ve or CON/CsA; ${ }^{\mathrm{b}} \mathrm{p}<$ 0.01 vs. IPC. c mPTP opening in $\mathrm{PKO}$ after IR. $n=6-7 /$ group. ${ }^{a} \mathrm{p}>0.05$ vs. NIS and $\mathrm{p}<$ 0.01 vs. IPC; ${ }^{\mathrm{b}} \mathrm{p}<0.01$ vs. IPC; ${ }^{\mathrm{c}} \mathrm{p}<0.01$ vs. CON.

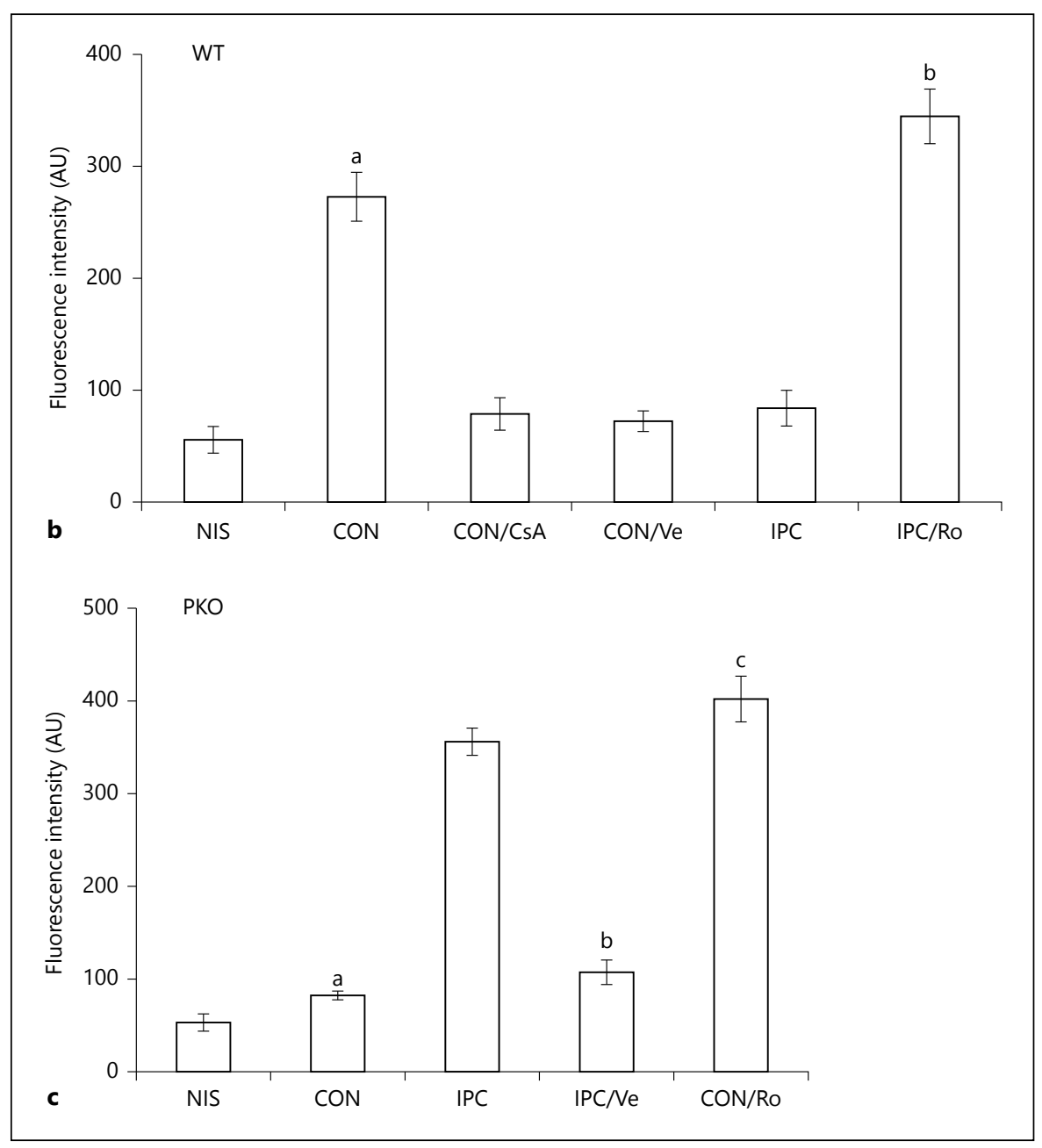


Fig. 7. A hypothesis of IPC-induced cardioprotection. IPC inactivates PTEN and decreases dephosphorylation of PIP3, which is produced by PI3K. PIP3 elevation causes Akt activation. Activated Akt promotes the localization of PDE4D to the caveolae at the plasma membrane through $\beta$-arrestin (Arr) and thereby induces the compartmentalization of cAMP signaling, limiting later increase in PKA activity and L-type calcium channel (LC) opening in response to lethal IR. This prevents activation of caspases and cell death from calcium overload and MPTP opening in reperfused hearts. $\mathrm{PM}=$ Plasma membrane; $\mathrm{Mt}=$ mitochondria.

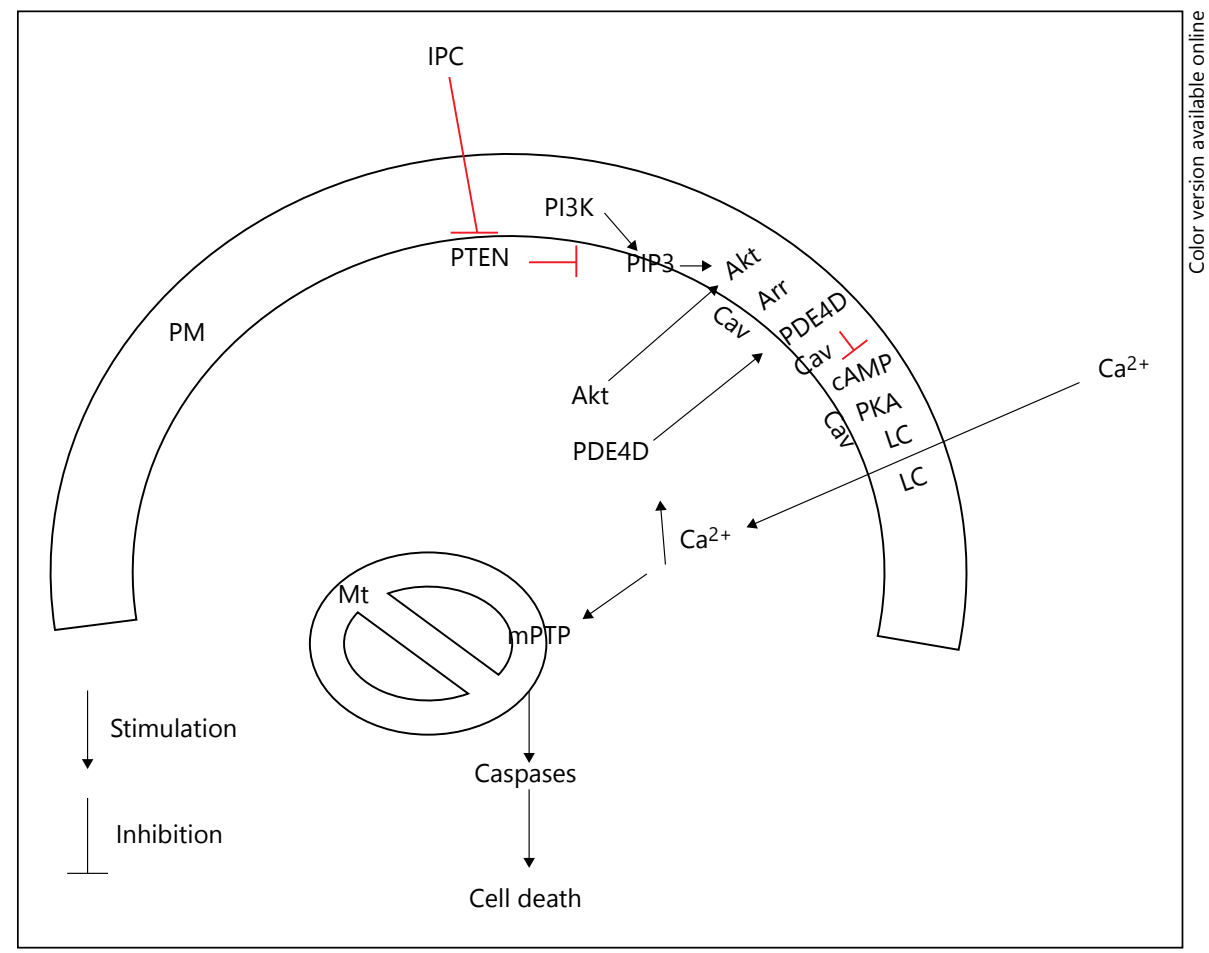

Many studies have reported that IPC activates the $\mathrm{PI}$ KK/Akt signaling pathway and protects the heart from IR injury $[13,16]$. However, the role of PTEN in IPC is not fully understood. In the present study, we showed that IPC inhibits Akt phosphorylation in PTEN-deficient hearts. It suggests that Akt requires PI3K and PTEN for its activation. IPC increases Akt phosphorylation in the myocardium of WT rats [13]. However, brief ischemia without reperfusion has been shown to cause a modest increase in Akt phosphorylation [29]. Ischemia decreases PTEN protein levels in the heart. PTEN inactivation itself can be sufficient to increase Akt phosphorylation if PI3K activity remains unchanged. As a protein enzyme, PI3K is likely impaired by ischemia. Early reperfusion further suppresses PTEN activity through reactive oxygen species [29]. Although PI3K is essential for PIP3 production, which causes Akt activation, the present study suggests PI3K itself is insufficient to activate Akt in the preconditioned heart. Therefore, despite the importance of PI3K, PTEN inactivation is the key factor in Akt activation and IPC induction. PI3K and PTEN may also be associated with activation of other reperfusion injury salvage kinases such as p42/p44 [29-31]. However, their role in IPC is less certain $[32,33]$.

PDE4D plays an important role in regulating the spatiotemporal dynamics of cAMP signals in rodent cardiomyo- cytes [20]. At the plasma membrane, L-type $\mathrm{Ca}^{2+}$ channel activity is associated with compartmentalized cAMP signaling through PKA $[20,21]$. L-type $\mathrm{Ca}^{2+}$ channels, PKA, $\beta$-arrestin and Akt have been identified in the caveolae of cardiac myocytes [21, 34]. $\beta$-Arrestin may be the key for recruiting PDE4D to the plasma membrane. It has been reported that $\beta$-arrestin is involved in the modulation of $\beta_{2}$-adrenoceptor signaling and induction of IPC [23, 3537]. In the present study, we demonstrate that $\beta$-arrestin is associated with PDE4D and Akt in preconditioned membrane fractions. Akt has been shown to form a complex with PDE4D through $\beta$-arrestin at the plasma membrane, promoting localization of PDE4D [38]. Consistent with the finding, the present study showed that IPC-induced Akt activation increases localization of PDE4D to caveolae, suggesting that PDE4D may mediate the compartmentalization of CAMP at the plasma membrane and limit later increase in L-type $\mathrm{Ca}^{2+}$ channel activity by reducing local PKA activity in the preconditioned heart.

IPC has been shown to inhibit necrosis and apoptosis in the infarcted heart through the PI3K/PTEN/Akt signaling pathway $[13,14,39]$. However, necrotic cell death is critically related to calcium overload and subsequent $\mathrm{mPTP}$ opening while apoptotic cell death is promoted by release of cytochrome $c$ [40]. Akt regulates Bcl-2 family proteins and blocks the release of cyto- 
chrome $c$ from mitochondria $[40,41]$. In the present study, our results suggest that Akt may inhibit calcium overload in the ischemic heart by increasing PDE4D localization to the plasma membrane. This provides new insights into the molecular mechanism by which IPC inhibits both necrosis and apoptosis. Our observations are consistent with previous reports in which Cav-3 deficiency or a defect in the plasma membrane resulted in loss of IPC $[11,42]$. GSK-3 $\beta$ has been implicated in the inhibition of MPTP opening, and GSK-3 $\beta$ is a substrate of Akt [43]. Further studies are needed to determine whether Akt regulates GSK-3 $\beta$ at the plasma membrane. Based on the present study and previous observations, a hypothesis of IPC-induced cardioprotection is proposed (fig. 7).
In conclusion, IPC inactivates PTEN and promotes PDE4D localization to the plasma membrane through Akt, leading to inhibition of calcium overload in ischemic hearts and MPTP opening after IR.

\section{Acknowledgments}

This work was supported by Public Health Service grants HL88071 and HL65608 from the National Heart, Lung and Blood Institute, National Institutes of Health.

\section{Conflict of Interest}

None.

\section{References}

-1 Roger VL, Go AS, Lloyd-Jones DM, et al: Heart disease and stroke statistics - 2011 update: a report from the American Heart Association. Circulation 2011;123:e18e209.

-2 Yellon DM, Hausenloy DJ: Myocardial reperfusion injury. N Engl J Med 2007;357:1121-1135.

-3 Murry CE, Jennings RB, Reimer KA: Preconditioning with ischemia: a delay of lethal cell injury in ischemic myocardium. Circulation 1986;74:1124-1136.

4 Hausenloy DJ, Yellon DM: The therapeutic potential of ischemic conditioning: an update. Nat Rev Cardiol 2011;8:619-629.

5 Javadov SA, Clarke S, Das M, Griffiths EJ, Lim $\mathrm{KH}$, Halestrap AP: Ischaemic preconditioning inhibits opening of mitochondrial permeability transition pores in the reperfused rat heart. J Physiol 2003;549:513-524.

$\checkmark 6$ Hausenloy DJ, Duchen MR, Yellon DM: Inhibiting mitochondrial permeability transition pore opening at reperfusion protects against ischaemia-reperfusion injury. Cardiovasc Res 2003;60:617-625.

7 Juhaszova M, Zorov DB, Kim SH, Pepe S, Fu Q, Fishbein KW, Ziman BD, Wang S, Ytrehus K, Antos CL, Olson EN, Sollott SJ: Glycogen synthase kinase-3beta mediates convergence of protection signaling to inhibit the mitochondrial permeability transition pore. J Clin Invest 2004;113:1535-1549.

8 Oudit GY, Sun H, Kerfant BG, Crackower MA, Penninger JM, Backx PH: The role of phosphoinositide- 3 kinase and PTEN in cardiovascular physiology and disease. J Mol Cell Cardiol 2004:37:449-471.

-9 Brazil DP, Park J, Hemmings BA: PKB binding proteins. Getting in on the Akt. Cell 2002; 111:293-303.

10 Patel HH, Head BP, Petersen HN, Niesman IR, Huang D, Gross GJ, Insel PA, Roth DM:
Protection of adult rat cardiac myocytes from ischemic cell death: role of caveolar microdomains and delta-opioid receptors. Am J Physiol 2006;291:H344-H350.

-11 Tsutsumi YM, Horikawa YT, Jennings MM, Kidd MW, Niesman IR, Yokoyama U, Head BP, Hagiwara Y, Ishikawa Y, Miyanohara A, Patel PM, Insel PA, Patel HH, Roth DM: Cardiac-specific overexpression of caveolin-3 induces endogenous cardiac protection by mimicking ischemic preconditioning. Circulation 2008;118:1979-1988.

12 Sun J, Murphy E: Calcium-sensing receptor: a sensor and mediator of ischemic preconditioning in the heart. Am J Physiol 2010; 299:H1309-H1317.

13 Tong H, Chen W, Steenbergen C, Murphy E: Ischemic preconditioning activates phosphatidylinositol-3-kinase upstream of protein kinase C. Circ Res 2000;87:309-315.

14 Cai ZP, Shen Z, Van Kaer L, Becker LC: Ischemic preconditioning-induced cardioprotection is lost in mice with immunoproteasome subunit low molecular mass polypeptide-2 deficiency. FASEB J 2008;22: 4248-4257.

15 Krieg T, Qin Q, Philipp S, Alexeyev MF, Cohen MV, Downey JM: Acetylcholine and bradykinin trigger preconditioning in the heart through a pathway that includes Akt and NOS. Am J Physiol 2004;287:H2606H2611.

16 Matsui T, Rosenzweig A: Convergent signal transduction pathways controlling cardiomyocyte survival and function: the role of PI 3-kinase and Akt. J Mol Cell Cardiol 2005;38: 63-71.

$\checkmark 17$ Balijepalli RC, Foell JD, Hall DD, Hell JW, Kamp TJ: Localization of cardiac L-type $\mathrm{Ca}(2+)$ channels to a caveolar macromolecular signaling complex is required for beta(2)- adrenergic regulation. Proc Natl Acad Sci USA 2006;103:7500-7505.

18 Gratton JP, Bernatchez P, Sessa WC: Caveolae and caveolins in the cardiovascular system. Circ Res 2004;94:1408-1417.

19 Tang Z, Scherer PE, Okamoto T, Song K, Chu C, Kohtz DS, Nishimoto I, Lodish HF, Lisanti MP: Molecular cloning of caveolin-3, a novel member of the caveolin gene family expressed predominantly in muscle. J Biol Chem 1996; 271:2255-2261.

-20 Leroy J, Abi-Gerges A, Nikolaev VO, Richter W, Lechêne P, Mazet JL, Conti M, Fischmeister R, Vandecasteele G: Spatiotemporal dynamics of beta-adrenergic cAMP signals and L-type $\mathrm{Ca}^{2+}$ channel regulation in adult rat ventricular myocytes: role of phosphodiesterases. Circ Res 2008;102:1091-1100.

21 Verde I, Vandecasteele G, Lezoualc'h F, Fischmeister R: Characterization of the cyclic nucleotide phosphodiesterase subtypes involved in the regulation of the L-type $\mathrm{Ca}^{2+}$ current in rat ventricular myocytes. Br J Pharmacol 1999;127:65-74.

22 Lehnart SE, Wehrens XH, Reiken S, Warrier S, Belevych AE, Harvey RD, Richter W, Jin SL, Conti M, Marks AR: Phosphodiesterase 4D deficiency in the ryanodine-receptor complex promotes heart failure and arrhythmias. Cell 2005; 123:25-35.

23 Perry SJ, Baillie GS, Kohout TA, McPhee I, Magiera MM, Ang KL, Miller WE, McLean AJ, Conti M, Houslay MD, Lefkowitz RJ: Targeting of cyclic AMP degradation to beta 2 -adrenergic receptors by beta-arrestins. Science 2002;298:834-836.

-24 Zu L, Bedja D, Fox-Talbot K, Gabrielson KL, Van Kaer L, Becker LC, Cai ZP: Evidence for a role of immunoproteasomes in regulating cardiac muscle mass in diabetic mice. J Mol Cell Cardiol 2010;49:5-15. 
25 Zu L, Zheng X, Wang B, Parajuli N, Steenbergen C, Becker LC, Cai ZP: Ischemic preconditioning attenuates mitochondrial localization of PTEN induced by ischemia-reperfusion. Am J Physiol 2011;300:H2177-H2186.

26 Oka N, Asai K, Kudej RK, Edwards JG, Toya Y, Schwencke C, Vatner DE, Vatner SF, Ishikawa Y: Downregulation of caveolin by chronic beta-adrenergic receptor stimulation in mice. Am J Physiol 1997;273:C1957C1962.

27 Talukder MA, Kalyanasundaram A, Zhao X, Zuo L, Bhupathy P, Babu GJ, Cardounel AJ, Periasamy M, Zweier JL: Expression of SERCA isoform with faster $\mathrm{Ca}^{2+}$ transport properties improves postischemic cardiac function and $\mathrm{Ca}^{2+}$ handling and decreases myocardial infarction. Am J Physiol 2007; 293:H2418-H2428.

28 Petronilli V, Miotto G, Canton M, Brini M, Colonna R, Bernardi P, Di Lisa F: Transient and long-lasting openings of the mitochondrial permeability transition pore can be monitored directly in intact cells by changes in mitochondrial calcein fluorescence. Biophys J 1999;76:725-734.

29 Cai Z, Semenza GL: PTEN activity is modulated during ischemia and reperfusion: involvement in the induction and decay of preconditioning. Circ Res 2005;97:1351-1359.

30 Ruan H, Li J, Ren S, Gao J, Li G, Kim R, Wu $\mathrm{H}$, Wang $\mathrm{Y}$ : Inducible and cardiac specific PTEN inactivation protects ischemia/reperfusion injury. J Mol Cell Cardiol 2009;46:193200.
31 Crackower MA, Oudit GY, Kozieradzki I, Sarao R, Sun H, Sasaki T, Hirsch E, Suzuki A, Shioi T, Irie-Sasaki J, Sah R, Cheng HY, Rybin VO, Lembo G, Fratta L, Oliveira-dos-Santos AJ, Benovic JL, Kahn CR, Izumo S, Steinberg SF, Wymann MP, Backx PH, Penninger JM: Regulation of myocardial contractility and cell size by distinct PI3K-PTEN signaling pathways. Cell 2002;110:737-749.

32 Kunuthur SP, Mocanu MM, Hemmings BA, Hausenloy DJ, Yellon DM: The Akt1 isoform is an essential mediator of ischaemic preconditioning. J Cell Mol Med 2012;16:1739-1749.

33 Mocanu MM, Bell RM, Yellon DM: PI3 kinase and not $\mathrm{p} 42 / \mathrm{p} 44$ appears to be implicated in the protection conferred by ischemic preconditioning. J Mol Cell Cardiol 2002;34 661-668.

34 Weiss S, Oz S, Benmocha A, Dascal N: Regulation of cardiac L-type $\mathrm{Ca}^{2+}$ channel CaV1.2 via the $\beta$-adrenergic-cAMP-protein kinase $\mathrm{A}$ pathway: old dogmas, advances, and new uncertainties. Circ Res 2013;113:617-631.

35 Nichols CB, Rossow CF, Navedo MF, Westenbroek RE, Catterall WA, Santana LF, McKnight GS: Sympathetic stimulation of adult cardiomyocytes requires association of AKAP5 with a subpopulation of L-type calcium channels. Circ Res 2010;107:747-756.

36 Xiang Y, Naro F, Zoudilova M, Jin SL, Conti M, Kobilka B: Phosphodiesterase 4D is required for beta2 adrenoceptor subtype-specific signaling in cardiac myocytes. Proc Natl Acad Sci USA 2005;102:909-914.
7 Tong H, Bernstein D, Murphy E, Steenbergen $\mathrm{C}$ : The role of beta-adrenergic receptor signaling in cardioprotection. FASEB J 2005; 19 : 983-985.

38 Bjørgo E, Solheim SA, Abrahamsen H, Baillie GS, Brown KM, Berge T, Okkenhaug K, Houslay MD, Taskén K: Cross talk between phosphatidylinositol 3-kinase and cyclic AMP (cAMP)-protein kinase A signaling pathways at the level of a protein kinase B/beta-arrestin/ cAMP phosphodiesterase 4 complex. Mol Cell Biol 2010;30:1660-1672.

39 Hausenloy DJ, Tsang A, Mocanu MM, Yellon DM: Ischemic preconditioning protects by activating prosurvival kinases at reperfusion. Am J Physiol 2005;288:H971-H976.

40 Murphy E, Steenbergen C: Mechanisms underlying acute protection from cardiac ischemia-reperfusion injury. Physiol Rev 2008;88: 581-609.

41 Fujio Y, Nguyen T, Wencker D, Kitsis RN, Walsh K: Akt promotes survival of cardiomyocytes in vitro and protects against ischemiareperfusion injury in mouse heart. Circulation 2000;101:660-667.

42 Cao CM, Zhang Y, Weisleder N, Ferrante C, Wang X, Lv F, Zhang Y, Song R, Hwang M, Jin L, Guo J, Peng W, Li G, Nishi M, Takeshima H, Ma J, Xiao RP: MG53 constitutes a primary determinant of cardiac ischemic preconditioning. Circulation 2010;121:2565-2574.

43 Juhaszova M, Zorov DB, Yaniv Y, Nuss HB, Wang S, Sollott SJ: Role of glycogen synthase kinase-3beta in cardioprotection. Circ Res 2009; 104:1240-1252.
Cardioprotection Induced by Ischemic Preconditioning 